\title{
Biodiesel a partir de óleo de fritura: uma temática atual para abordagem das relações cts em uma sala de aula de química
}

\author{
Leandro de Araújo Azevedo \\ Claudia Cristina Cardoso Bejan \\ Angela Fernandes Campos
}

Maria Angela Vasconcelos de Almeida

\begin{abstract}
Resumo
O biodiesel obtido a partir do óleo de fritura foi proposto como uma temática para abordagem das relações CTS atreladas aos conteúdos, energia de ativação, catalisador, reação de transesterificação, entre outros. A metodologia contemplou as ações do Programa PIBID num contexto escolar que apresenta um modelo de gestão pedagógica inovador. Envolveu a elaboração de questionários, pré e pós-testes, intervenção didática com aulas teóricas e uso de vídeos sobre questões sociais como efeito estufa, aquecimento global e descarte inadequado de óleo de fritura em redes de esgoto; elaboração e aplicação de uma síntese do biodiesel etílico a partir do óleo de fritura doado pelos estudantes. A abordagem CTS proporcionou: evolução conceitual em relação às questões sociais aqui comentadas e relação da temática biodiesel com os conceitos químicos aqui expostos; desenvolvimento de atitudes nos alunos como o recolhimento de óleo de fritura de suas residências.
\end{abstract}

Palavras-chave: Biodiesel, óleo de fritura, reação de transesterificação.

\begin{abstract}
Biodiesel from waste frying oil: a current approach for STS relationships within a chemistry classroom

Biodiesel obtained from waste frying oil was proposed as an approach in STS relationships related to chemical contents, that is, activation energy, catalyzer, transesterification reaction, among others. The methodology was structured in accordance with the PIBID in a school setting that represents an innovative pedagogical management model. This consisted of questionnaires, pre and posttests, didactic intervention involving theoretical classes with use of videos to illustrate social issues as the greenhouse effect, global warming and unsuitable disposal of waste frying oil into sewage treatment systems. Ethylic biodiesel synthesis from domestic frying oil donated by students was also elaborated and applied. Approach in STS showed: conceptual evolution with respect to the aforementioned social questions and relation of the biodiesel issue to the chemical concepts discussed here; attitude development as collect of domestic frying oil by students.
\end{abstract}

Keywords: Biodiesel, frying oil, transesterification reaction 


\section{Introdução}

A crescente consciência de que a cultura científica e tecnológica não dá conta da complexidade dos problemas da sociedade tem levado à compreensão de que é preciso preparar as pessoas para participar e se posicionar em discussões públicas de problemas que afetam a sociedade e, para tal, é necessário promover a formação de uma cidadania que torne possível a compreensão das decisões técnico-científicas, isto é uma cidadania capacitada para compreendêlas e participar delas. Contudo, a ciência é percebida pela sociedade como um conhecimento neutro que representa a verdade sobre a natureza, basta lembrar situações de conflito no qual um dos oponentes cita o conhecimento científico e a discussão é prontamente encerrada.

A ciência e a tecnologia são decorrentes do processo de desenvolvimento humano, são duas disciplinas distintas com características diferentes, embora inter-relacionadas, na medida em que o processo tecnológico inclui o processo científico e vice-versa, existindo entre ambas as relações de interdependência. As ciências buscam a verdade científica sobre os fenômenos naturais a partir de resultados de testes experimentais que envolvem conceitos abstratos vinculados com situações e com projetos que nos fazem organizar o mundo. A tecnologia busca resolver problemas da sociedade pela aplicação do conhecimento científico e outros conhecimentos. Neste sentido não existe uma grande diferenciação entre a ciência e a técnica, embora as finalidades das ciências em relação à sociedade sejam mais facilmente mascaradas do que as influências e finalidades da tecnologia.

Segundo Santos et al (2011) o enfoque CTS tem três grandes pretensões: desmistificar o poder da ciência e da tecnologia que leva ao pleno desenvolvimento; favorecer a participação pública nas decisões de temáticas tecnocientíficas; renovação do currículo escolar incluindo as relações C\&T articuladas ao contexto social. Entretanto, as iniciativas acerca dos currículos que relacionam CTS no ensino médio ainda não são comuns e requerem perspectivas e metodologias inovadoras:

(...) diante do quadro apresentado pela educação brasileira, a implementação dessas orientações é uma tarefa complexa, pois há uma grande desvalorização do ensino de ciências, com ausência de políticas públicas de incentivo para a ocorrência de efetiva alfabetização científica. (Marcondes et al., 2009, p.282).

A aceitação das tecnologias energéticas congrega diferentes atores: os produtores, organizações ecológicas, as políticas públicas, o mercado, empresas petrolíferas, todos têm algo a dizer em relação à rejeição ou aceitação do seu uso. Em relação à diversidade de argumentos, as organizações ecológicas, por exemplo, defendem a posição de que os biocombustíveis de primeira geração não reduzem a emissão de $\mathrm{CO}_{2}$, além de destruírem os ecossistemas locais, mas aceitam o uso de biocombustíveis de segunda geração (Oltra \& Priolo, 2012). 
Como fica a situação das pessoas comuns neste cenário de diferentes posições e argumentos? Em termos gerais os biocombustíveis não trazem riscos ou benefícios para os indivíduos que na maioria possuem uma compreensão muito limitada e muitos não estão sensibilizados com as implicações ambientais, econômicas e sociais. Como participar enquanto cidadão se não houver oportunidade de vivenciar discussões sobre a temática? Portanto, a temática biocombustível é sem dúvida importante para ser discutida numa proposta de CTS relacionando com o meio ambiente, em especial quando discute a alternativa de utilizar como matéria prima o óleo de fritura produzindo o biodiesel de segunda geração.

O biodiesel é um biocombustível alternativo ao diesel de petróleo, apresentando propriedades de combustão muito próximas às do diesel, entretanto, é oriundo de matérias primas renováveis que contêm triglicerídeos, tais como, óleos vegetais, gorduras animais e óleos e gorduras residuais (OGR) (Thaiyasuit et al., 2012; Charpe \& Rathod, 2011). O biodiesel é constituído por uma mistura de ésteres alquílicos de ácidos graxos, que pode ser obtido a partir da reação de transesterificação entre triglicerídeos e álcoois de cadeia curta, na presença de um catalisador ácido ou alcalino, tendo a glicerina como co-produto (Fig. 1).

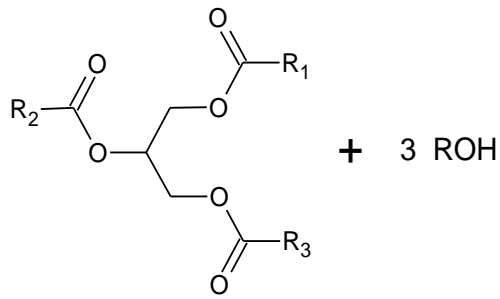

Triglicerídeo (Óleo ou Gordura)
Álcool

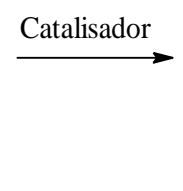

Glicerina
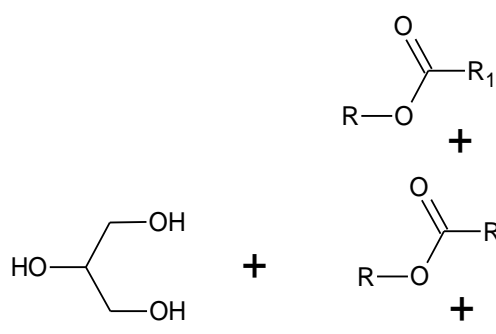<smiles>[R]OC([R])=O</smiles>

Mistura de Ésteres

(Biodiesel)

Figura 1: Síntese de biodiesel a partir da reação de transesterificação de triglicerídeos com álcool, em meio catalítico.

A transesterificação permite o uso de catalisadores, que amenizam as condições de síntese e alteram a velocidade da reação, diminuindo o tempo da reação. Os catalisadores alcalinos são os mais indicados frente aos catalisadores ácidos por permitirem maior velocidade da reação e maiores conversões do óleo em biodiesel em condições moderadas de temperatura (Lam et al., 2010). No entanto, o catalisador alcalino, quando em presença de água, promove a produção de sabão através da hidrólise do éster, dificultando a separação da fase glicérica e reduzindo o rendimento da reação. Dentre os catalisadores alcalinos destacam-se o hidróxido de sódio $(\mathrm{NaOH})$ e o hidróxido de potássio $(\mathrm{KOH})$, por permitirem baixo custo e condições mais brandas na etapa de reação e simplicidade dos equipamentos (Lam et al., 2010). 
O metanol é o álcool mais comumente usado na síntese do biodiesel devido às suas propriedades físico-químicas, baixo custo, por permitir condições mais brandas de produção e melhor separação de fases. Entretanto, se trata de um álcool tóxico, letal, não-renovável, oferece alto risco de explosão e que precisa ser manipulado com muita cautela. Como alternativa, o etanol vem sendo estudado como uma possibilidade promissora por não apresentar tais propriedades indesejadas do metanol, além de ser um álcool renovável, conferindo maior vantagem ambiental ao biodiesel. No entanto, o uso de etóxidos tende a aumentar a produção de sabões nas reações com catálise alcalina, além de apresentar maior custo e separação de fases mais complexas por permitir maior homogeinização entre a glicerina e o biodiesel (Cavalcante et al., 2010).

O uso de OGR resultante de processamento doméstico, comercial e industrial, como matéria prima na síntese do biodiesel tem como principal vantagem o fato de possibilitar a reciclagem, sendo esta uma forma muito atrativa de gerenciamento de resíduos, pois além de se utilizar de matéria-prima de baixo custo, geralmente considerada como lixo, diminui a degradação ambiental (Thaiyasuit et al., 2012). Apesar do pouco tempo que estes resíduos levam para se decompor, sua decomposição gera metano $\left(\mathrm{CH}_{4}\right)$, gás com poderoso potencial para aquecer o planeta. Além disso, o despejo desses resíduos nos ralos permite seu acúmulo nos encanamentos que pode causar entupimentos, refluxo de esgoto e até rompimentos nas redes de coleta. O OGR é largamente utilizado como matéria-prima na síntese do biodiesel em diversos países, tais como Austrália, China, Alemanha, Itália, Portugal, Reino Unido e nos EUA. Enquanto isso, no Brasil, seu uso ainda apresenta-se bastante tímido encontrando como principal dificuldade a logística de recolhimento devido, especialmente, ao despejo de modo indevido, consequência da inexistência de uma lei que nos obrigue ou incentive a coleta e destinação do OGR, e da falta de uma educação ambiental mais agressiva nesse sentido (Bejan e Silva, 2010).

Pelo exposto, a inserção da temática biodiesel numa discussão em um contexto escolar que articula as relações Ciência, Tecnologia, Sociedade (CTS) com conceitos químicos como funções orgânicas, reação de transesterificação, catalisador, energia de ativação, temperatura, etc, pode se constituir, em termos metodológicos, numa estratégia de ensino que desenvolva nos alunos conhecimentos, procedimentos e atitudes relevantes para se posicionarem criticamente frente às situações cotidianas que Ihes são impostas. Assim sendo, o ensino se apresenta com uma finalidade mais abrangente, pois, além da abordagem conceitual, os impactos sociais relativos às implicações da ciência e tecnologia são trazidos para sala de aula como requisitos essenciais na formação do cidadão (Marcondes et al., 2009). O professor dentro desse contexto deve estar preparado no sentido de saber articular o novo, a fim de permitir ao aluno uma reflexão da problemática discutida no que tange à ciência e tecnologia. Isso é, sem dúvida, um grande desafio. Estudos nessa linha de investigação (Acevedo Romero e Acevedo Diaz, 2002; Firme e Amaral, 2011) apontam algumas dificuldades da prática docente pautada nas relações 
CTS, tais como: ausência de informações técnicas e científicas sobre o tema, complexidade científica na abordagem de alguns temas, articulação adequada de conceitos científicos com questões tecnológicas associadas a um tema social relevante e material didático adequado que suporte as discussões de temas específicos em sala de aula.

Cientes dessas questões e esperando contribuir nesse sentido, o presente trabalho visa combinar desenvolvimento tecnológico com equidade social e qualidade ambiental, estreitando a já existente parceria entre a Universidade Federal Rural de Pernambuco - UFRPE e a Escola de Referência em Ensino Médio Professor Cândido Duarte (EREM - Professor Cândido Duarte), pertencente ao projeto de escolas integrais do estado de Pernambuco, por meio do Programa Institucional de Bolsa de Iniciação a Docência (PIBID). Sob essa perspectiva, esse estudo teve como objetivo analisar de que forma uma intervenção pautada nas relações CTS contribuiu para a aprendizagem de temáticas ambientais por alunos da escola EREM - Professor Cândido Duarte.

\section{Metodologia}

O processo investigativo foi norteado principalmente pela abordagem qualitativa, devido ao fato deste estudo abranger algumas das recomendações para as pesquisas em Educação (OLIVEIRA, 2003; LÜDKE; ANDRÉ, 1986), a saber: i) sobre o estudo de conceitos científicos no seu contexto social, nesse caso, temáticas que envolvem aquecimento global, efeito estufa, produção de biodiesel, entre outros e dos conceitos químicos a eles atrelados, considerando-os como um fenômeno complexo e de natureza social; ii) o ambiente natural da sala de aula como fonte direta de dados e um dos pesquisadores como observador participante e indispensável no processo investigativo, nesse caso, um licenciando do PIBID; iii) o contato direto e de duração intermediária da pesquisadora e co-autora desse trabalho com os sujeitos da pesquisa e a sua preocupação em entender o que se processa no ambiente da pesquisa; iv) o caráter descritivo adotado, que se preocupa não apenas com o resultado final, mas com todo o processo de investigação e de obtenção dos dados.

Apesar dessa predominância, considerou-se também que a abordagem qualitativa e a quantitativa não são excludentes e se complementam (OLIVEIRA, 2003). Por isso sendo esta última também utilizada para mensurar as características gerais dos dados coletados (figuras 5 a 7) e reforçar o tratamento qualitativo dado à interpretação dos dados.

\section{Contexto de elaboração da proposta de intervenção}

As atividades foram elaboradas no Laboratório de Óleo e Biodiesel (LOB) do Departamento de Química (DQ) da UFRPE. Uma das funções do LOB está no recebimento de doações de óleos de fritura. Essas doações são, em sua maioria, provenientes dos alunos da 
UFRPE, de escolas públicas e de comunidades no entorno da UFRPE envolvidas nas várias atividades de extensão promovidas por nosso grupo. Algumas dessas atividades podem ser vistas no blog criado e desenvolvido pelos alunos bolsistas (http://lob-ufrpe.blogspot.com). O óleo de fritura é catalogado, tratado e doado para a Usina Experimental de Biodiesel do Centro Tecnológico do Nordeste (CETENE) localizado na cidade de Caetés/PE, que realiza a produção de biodiesel.

\section{Contexto de desenvolvimento do trabalho}

Ao final de 2009 a UFRPE firmou parceria com a Secretaria de Educação de Pernambuco (SEE) para desenvolver o projeto: "Escola de Referência e de Formação de Professores para o Ensino Médio Professor Cândido Duarte", que inclui a implantação de modelo de gestão administrativa e pedagógica inovador em educação pública. $O$ projeto se propõe a manter um programa de formação pedagógica em ação para os professores e busca resgatar a cidadania, na pedagogia da presença e do exemplo, priorizando a educação para valores, formando jovens solidários, autônomos e produtivos. Semanalmente é realizada uma reunião com toda a equipe docente, gestores e a coordenação geral do projeto (ALMEIDA et al, 2010).

\section{Sujeitos da Pesquisa}

No início do semestre letivo os pibidianos apresentam os projetos para os alunos e eles que escolhem se envolver nas propostas. Nesse sentido, participaram da intervenção cerca de 20 alunos (denominados aqui $\mathrm{A} 1, \mathrm{~A} 2$...A20) do segundo ano do ensino médio. As atividades foram desenvolvidas pelo bolsista do PIBID com a colaboração do professor de Química e com o conhecimento da gestão da escola.

\section{Atividades desenvolvidas no LOB Organização do material a ser exposto na escola}

Foi confeccionado um banner (figura 2) com orientações para doação do óleo de fritura e evidenciava as causas ambientais provocadas pelo descarte incorreto. Isso foi feito como forma de motivar os estudantes acerca da doação do óleo de fritura na escola. As orientações também foram divulgadas em sala de aula. 


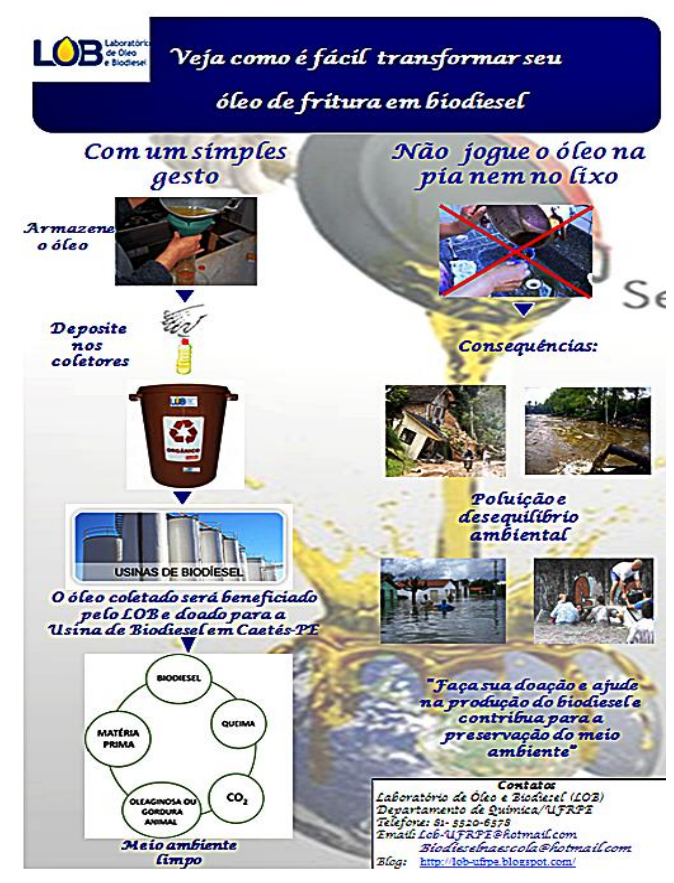

Figura 2. Banner de divulgação sobre doação do óleo de fritura e impacto ambiental proveniente do descarte incorreto.

\section{Adaptação de um balde para coleta de óleo de fritura}

A adaptação de um balde, exposto no banner (figura 2), foi feita com pintura do recipiente na coloração marrom, evidenciando a cor de reciclagem de materiais orgânicos e etiquetagem do mesmo com a logomarca LOB/DO/UFRPE. O balde foi colocado numa área de grande circulação na escola, sendo utilizado para o recolhimento do óleo de fritura doado pelos alunos.

\section{Elaboração dos questionários de sondagem}

Foram elaborados três questionários (pré-testes) que contemplavam: (i)- temáticas ambientais, como efeito estufa, aquecimento global (tabela 1); (ii)- abundância de água para consumo humano, oxigênio dissolvido em sistemas aquosos e descarte do óleo de fritura (tabela 2); (iii)- reciclagem do óleo de fritura e produção de biodiesel (tabela 3). Nas tabelas 1-3 são apresentadas as questões propostas bem como os critérios adotados para análise das respostas dos alunos. Esses critérios foram nivelados em resposta satisfatória (RS), parcialmente satisfatória (RPS) e não satisfatória (RN). As respostas não satisfatórias são aquelas que não se enquadram nas categorias satisfatória e parcialmente satisfatória. Nas tabelas estão presentes os referenciais teóricos que deram suporte aos critérios estabelecidos. As mesmas questões foram abordadas no pós-teste. Os pré-testes foram aplicados no momento anterior à intervenção didática e os pós- 
testes após um período de uma semana de vivência da intervenção didática que consistiu em diversas atividades.

Tabela 1. Questionário sobre efeito estufa, aquecimento global e os critérios de análise.

\begin{tabular}{|c|c|c|}
\hline \multirow[t]{2}{*}{ QUESTÕES PROPOSTAS } & \multicolumn{2}{|l|}{ CRITÉRIOS DE ANÁLISE } \\
\hline & Resposta Satisfatória (RS) & $\begin{array}{c}\text { Resposta } \\
\text { Parcialmente } \\
\text { Satisfatória } \\
\text { (RPS) }\end{array}$ \\
\hline $\begin{array}{l}\text { 1- O que você sabe } \\
\text { sobre efeito estufa, ele } \\
\text { é bom ou ruim para o } \\
\text { nosso planeta, } \\
\text { explique? }\end{array}$ & $\begin{array}{l}\text { O efeito estufa é o aumento de temperatura que a } \\
\text { Terra apresenta em função da retenção de calor } \\
\text { proveniente do Sol, propiciada pela presença de } \\
\text { certos gases na atmosfera. Esse efeito evita que a } \\
\text { Terra esfrie em excesso, propiciando assim as } \\
\text { formas mais variadas de vida na terra (Silva et al., } \\
\text { 2009). }\end{array}$ & $\begin{array}{l}\text { Considera que } \\
\text { o efeito estufa } \\
\text { é um } \\
\text { fenômeno } \\
\text { importante } \\
\text { para o } \\
\text { planeta. }\end{array}$ \\
\hline $\begin{array}{l}\text { 2- O que é aquecimento } \\
\text { global? }\end{array}$ & $\begin{array}{l}\text { O aumento do teor atmosférico dos gases-estufa } \\
\text { leva a um maior bloqueio da radiação, } \\
\text { consequentemente, pode causar um aumento do } \\
\text { efeito estufa: aquecimento da atmosfera e aumento } \\
\text { da temperatura da superfície terrestre (Tolentino e } \\
\text { Rocha Filho, 1998). }\end{array}$ & $\begin{array}{l}\text { Considera que } \\
\text { é um } \\
\text { fenômeno } \\
\text { provocado } \\
\text { pelo excesso } \\
\text { de calor. }\end{array}$ \\
\hline $\begin{array}{l}\text { 3- Quais os gases que } \\
\text { você conhece que } \\
\text { contribuem para o } \\
\text { aquecimento global? }\end{array}$ & $\begin{array}{l}\text { Vapor d'água, dióxido de carbono, alguns óxidos de } \\
\text { nitrogênio (mais especificamente o } \mathrm{N}_{2} \mathrm{O} \text { ), metano, } \\
\text { óxidos de enxofre, entre outros (Silva et al., 2009). }\end{array}$ & $\begin{array}{l}\text { Citam pelo } \\
\text { menos dois } \\
\text { tipos de gases. }\end{array}$ \\
\hline $\begin{array}{l}\text { 4- Quais as alternativas } \\
\text { que podem minimizar } \\
\text { as emissões dos gases } \\
\text { que contribuem para o } \\
\text { aquecimento global? }\end{array}$ & $\begin{array}{l}\text { Iniciativas e ações contra a destruição de florestas, } \\
\text { utilização de transportes coletivos e bicicleta, } \\
\text { revisão periódica de veículos automotivos, utilização } \\
\text { de combustíveis como o álcool e o biodiesel, } \\
\text { redução desperdício de água, entre outras (Kovalski } \\
\qquad \text { e Ana, 2007). }\end{array}$ & $\begin{array}{l}\text { Citam pelo } \\
\text { menos três } \\
\text { alternativas. }\end{array}$ \\
\hline
\end{tabular}


Tabela 2. Questionário sobre abundância de água, oxigênio dissolvido em sistemas aquosos e descarte de óleo de fritura.

\begin{tabular}{|c|c|c|}
\hline \multirow{2}{*}{$\begin{array}{l}\text { QUESTÕES } \\
\text { PROPOSTAS }\end{array}$} & \multicolumn{2}{|l|}{ CRITÉRIOS DE ANÁLISE } \\
\hline & Resposta Satisfatória (RS) & $\begin{array}{c}\text { Resposta } \\
\text { Parcialmente } \\
\text { Satisfatória (RPS) }\end{array}$ \\
\hline $\begin{array}{l}\text { 1- Existe água para } \\
\text { consumo humano em } \\
\text { abundância no nosso } \\
\text { planeta? Justifique sua } \\
\text { resposta. }\end{array}$ & $\begin{array}{l}\text { Não. Quanto maior a população maior a } \\
\text { demanda por água, que já se encontra em } \\
\text { situação crítica na maior parte do planeta } \\
\text { (Cortez, 2004). }\end{array}$ & $\begin{array}{l}\text { Considera que não } \\
\text { existe água potável } \\
\text { em abundância. }\end{array}$ \\
\hline $\begin{array}{l}\text { 2- Existe oxigênio } \\
\text { dissolvido na } \\
\text { água? Discuta. }\end{array}$ & $\begin{array}{l}\text { Sim, dentre os gases dissolvidos na água, o } \\
\text { oxigênio é um dos mais importantes na } \\
\text { dinâmica e caracterização dos ecossistemas } \\
\text { aquáticos (Esteves, 1998). }\end{array}$ & Afirma que sim. \\
\hline $\begin{array}{c}\text { 3- Há um equilíbrio } \\
\text { químico gasoso entre } \\
\text { a atmosfera com a } \\
\text { água? Justifique sua } \\
\text { resposta. }\end{array}$ & $\begin{array}{l}\text { Sim. A presença do } \mathrm{O}_{2} \text { na água se deve, em } \\
\text { parte, à dissolução do ar atmosférico na água } \\
\text { (Fiorucci e Edemar, 2005). }\end{array}$ & Afirma que sim. \\
\hline $\begin{array}{l}\text { 4- O óleo de fritura } \\
\text { jogado indevidamente } \\
\text { nos ralos pode } \\
\text { contribuir para a } \\
\text { mortandade da vida } \\
\text { aquática? Justifique } \\
\text { sua resposta. }\end{array}$ & $\begin{array}{l}\text { O óleo descartado acaba chegando aos rios e } \\
\text { até mesmo ao oceano, através das tubulações. } \\
\text { Cria-se assim uma barreira que dificulta a } \\
\text { entrada de luz e bloqueia a oxigenação da água. } \\
\text { Esse fato pode comprometer a base da cadeia } \\
\text { alimentar aquática (fitoplânctons), causando } \\
\text { um desequilíbrio ambiental, comprometendo a } \\
\text { vida (Rabelo e Ferreira, 2009). }\end{array}$ & $\begin{array}{l}\text { Considera que diminui } \\
\text { a oxigenação da água. }\end{array}$ \\
\hline
\end{tabular}


Tabela 3. Reciclagem do óleo de fritura e produção de biodiesel.

\begin{tabular}{|c|c|c|}
\hline QUESTÕES PROPOSTAS & \multicolumn{2}{|c|}{ CRITÉRIOS DE ANÁLISE } \\
\hline $\begin{array}{c}\text { Resposta Satisfatória (RS) } \\
\text { e o óleo é líquido à } \\
\text { temperatura ambiente? }\end{array}$ & $\begin{array}{c}\text { Nos óleos predominam ligações insaturadas e nas } \\
\text { gorduras ligações saturadas (Castro, 2011). }\end{array}$ & $\begin{array}{c}\text { Parcialmente } \\
\text { Satisfatória } \\
\text { (RPS) }\end{array}$ \\
\hline $\begin{array}{c}\text { 1- Por que decorrente } \\
\text { da estrutura } \\
\text { se tem para reciclagem do } \\
\text { óleo de fritura? }\end{array}$ & $\begin{array}{c}\text { Biodiesel, produção de sabão, de massa de } \\
\text { vidraceiro e de ração animal (Costa Neto et al., } \\
\text { 2000). }\end{array}$ & $\begin{array}{c}\text { Cita pelo } \\
\text { menos uma } \\
\text { alternativa. }\end{array}$ \\
\hline $\begin{array}{c}\text { 3- É necessário mudança no } \\
\text { motor do ciclo diesel para } \\
\text { receber o biodiesel? }\end{array}$ & $\begin{array}{c}\text { Não, o biodiesel apresenta as mesmas } \\
\text { propriedades de combustão no motor de ciclo }\end{array}$ & $\begin{array}{c}\text { Se o aluno } \\
\text { apenas disser } \\
\text { que não é }\end{array}$ \\
\hline $\begin{array}{c}\text { 4- Em sua opinião, quais as } \\
\text { matérias- primas que podem } \\
\text { servir para a produção de } \\
\text { biodiesel? }\end{array}$ & $\begin{array}{c}\text { As matérias-primas para a produção de biodiesel } \\
\text { são: óleos vegetais, gordura animal, óleos e } \\
\text { gorduras residuais etc. (Charpe \& Rathod, 2011). }\end{array}$ & $\begin{array}{c}\text { Cita pelo } \\
\text { menos duas } \\
\text { alternativas. }\end{array}$ \\
\hline
\end{tabular}




\section{Montagem das aulas teóricas e da atividade experimental}

A montagem das abordagens teóricas foi estruturada segundo o que está exposto na figura 3.

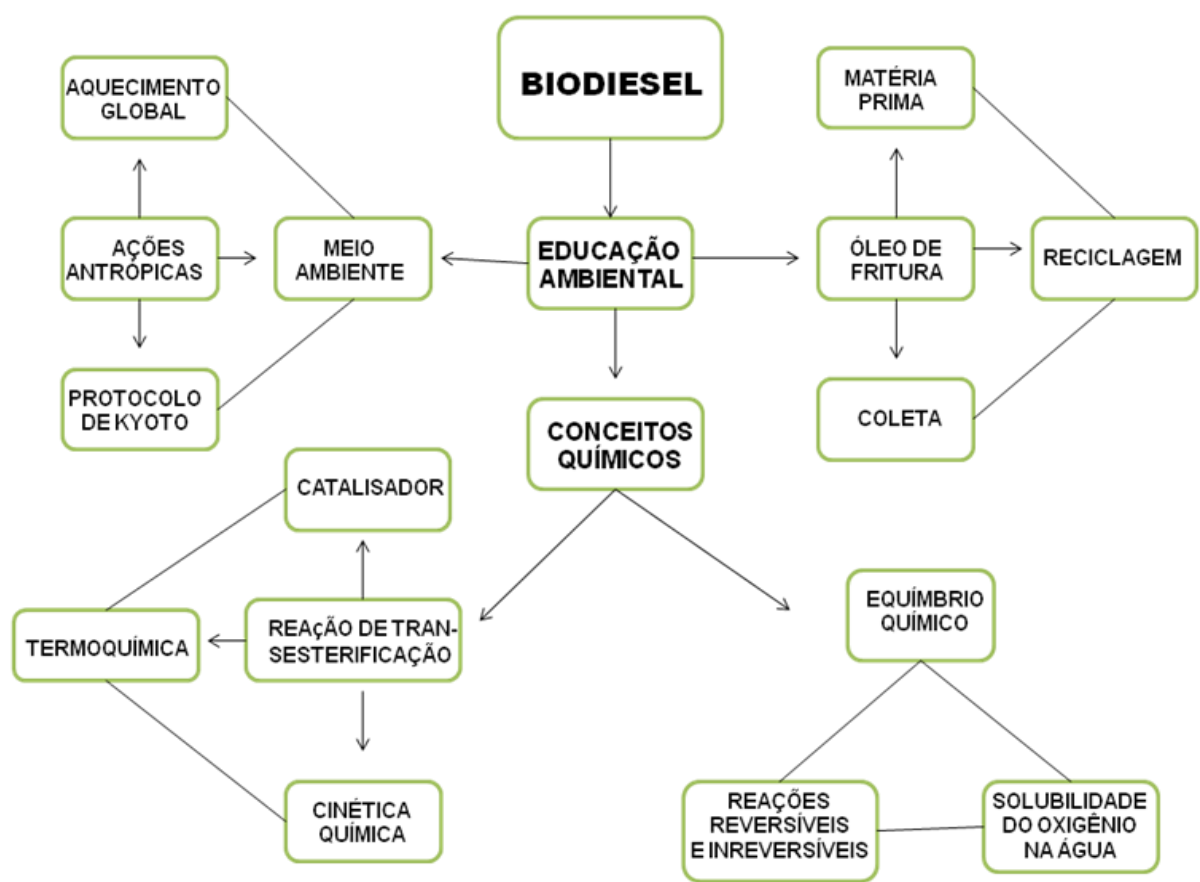

Figura 3. Esquema da estrutura utilizada para a abordagem teórica e experimental.

As abordagens teóricas I, II e III, descritas a seguir, contemplaram discussões envolvendo o meio ambiente, aquecimento global, ações antrópicas, protocolo de Kyoto, óleo de fritura, coleta, reciclagem, solubilidade do oxigênio na água e sua relação com equilíbrio químico. $A$ abordagem experimental contemplou discussões relacionadas à síntese do biodiesel com conteúdos de termoquímica e cinética química, como, catalisador, energia de ativação, reação de transesterificação, entre outros.

\section{Atividades desenvolvidas na EREM- Professor Cândido Duarte.}

Ao final do 10 semestre de 2011 a Professora Claudia C. C. Bejan, uma das autoras desse trabalho, proferiu a palestra para a comunidade escolar: "A importância da reciclagem do óleo comestivel para produção de biodiesel", que teve como objetivo sensibilizar a comunidade escolar sobre o problema ambiental do despejo do óleo comestível nos córregos e rios e também se configurou como estratégia para motivar os alunos a participarem do projeto. No início do segundo semestre os pibidianos apresentaram aos alunos da escola as propostas de projeto e o 
presente projeto foi escolhido por vinte alunos de uma das turmas da 2a série do ensino médio. Em seguida, o projeto foi desenvolvido a partir de diferentes atividades descritas a seguir:

Abordagem teórica l. Fez-se uso de um vídeo (http://www.youtube.com/watch?v=soicSlswjOk) que aborda sobre os problemas decorrentes do aquecimento global, os principais gases e suas estruturas moleculares, Protocolo de Kyoto e combustíveis veiculares alternativos (Biogás, Etanol e Biodiesel). Discutiu-se sobre o aumento da temperatura da terra decorrente das ações do homem, intensificada pelas indústrias que queimavam combustível para movimentar máquinas a vapores. Abordou-se sobre a queima de combustíveis fósseis derivados de petróleo e carvão, sendo a emissão de gases como $\mathrm{CO}_{2}, \mathrm{NO}_{2}, \mathrm{SO}_{2}$ responsáveis pela intensificação do efeito estufa que contribui para um aquecimento global, podendo provocar mudança permanente e irreversível no clima (Silva et al., 2009). Além disso, houve uma discussão sobre o protocolo de Kyoto (Godoy e João, 2007).

Abordagem teórica II. Envolveu uma discussão sobre os efeitos causados pela poluição da água proveniente do descarte de óleo de fritura na rede de esgoto. Discutiu-se que a poluição $\begin{array}{llll}\text { afeta o equilíbrio que envolve o oxigênio dissolvido (OD) na água, } & \mathrm{O}_{2}(\mathrm{~g}) & \mathrm{O}_{2}(\mathrm{aq}) \text {, }\end{array}$ no sentido de formação de $\mathrm{O}_{2}(\mathrm{~g})$, diminuindo a quantidade de $\mathrm{OD}$ e comprometendo a vida de animais e vegetais marinhos. Nesse momento fez-se uso de um vídeo (http://www.youtube.com/watch?v=soicSlswjOk) que mostra as consequências do acúmulo do óleo de fritura, como obstrução da rede de esgoto provocando um refluxo, ou seja, o retorno do esgoto para a residência. Ele alerta a população para não jogar óleo de fritura nos ralos, pias, etc. e há um incentivo acerca da doação. Também aborda sobre uma Organização Não Governamental (ONG) que coleta cerca de 300 mil litros de óleos de fritura por mês que são transformados em biodiesel, produzindo um combustível menos poluente e favorecendo a geração de empregos.

Abordagem teórica III. Discutiu-se sobre alguns aspectos históricos dos biocombustíveis derivados de óleos e gorduras e suas matérias-primas. Utilizou-se um vídeo (http://www.ecodesenvolvimento.org.br) que aborda o uso dos combustíveis fósseis desde a primeira revolução industrial e seu efeito na poluição ambiental contribuindo para o aquecimento global. O vídeo sugere como uma das alternativas para minimizar esses problemas o uso de biocombustível, entre eles o biodiesel. Nesse caso, a produção do mesmo pode ser feita por todos os óleos vegetais, gorduras animais e até mesmo os óleos residuais. Fez-se uma distinção, do ponto de vista químico, entre óleo e gordura em termos de estado físico e ligações insaturadas e saturadas. No óleo, há ligações insaturadas (duplas) e, à temperatura ambiente, apresenta-se no estado líquido, enquanto que a gordura contém ligações saturadas (simples) e se encontra no estado sólido.

Atividade experimental. Envolveu a síntese do biodiesel a partir do óleo de fritura coletado pelos estudantes de suas residências. Seguiu-se a metodologia disponível na literatura (Geris et. al, 2007), sendo feitas algumas adaptações, descritas a seguir: (i)-utilizou-se uma 
quantidade menor de óleo de fritura, $50 \mathrm{~mL}$, ao invés de $100 \mathrm{~mL}$; (ii)- substituiu-se o metanol por etanol; (iii) usou-se um erlenmeyer e um funil simples ao invés de um balão de reação e um condensador. Na reação de transesterificação, $1 \mathrm{~mol}$ de triglicerídeo reage com 3 mols de etanol, mas devido ao caráter reversível dessa reação, normalmente emprega-se um excesso de álcool para deslocar a reação no sentido de maior formação de biodiesel, de acordo com o Princípio de Le Chatelier (Santos e Pinto, 2009). A seguir são descritos os materiais, reagentes e o procedimento metodológico realizado.

\section{Materiais e reagentes}

Chapa de aquecimento e agitação, funil de decantação de $100 \mathrm{~mL}$, funil simples, erlenmeyer de $100 \mathrm{~mL}$, proveta de $50 \mathrm{~mL}$, termômetro, barra magnética, pirex, $\mathrm{KOH}$ P.A., etanol P.A, óleo de fritura, glicerina comercial.

\section{Procedimento}

Em um erlenmeyer de $100 \mathrm{~mL}$ foi adicionado $0,75 \mathrm{~g}$ de $\mathrm{KOH}$ e $17,5 \mathrm{~mL}$ de etanol, sob agitação magnética, por aproximadamente 5 minutos. Em seguida, adicionou-se $50 \mathrm{~mL}$ do óleo de fritura (Índice de acidez=3,48 mg KOH/g amostra e Teor de Umidade=1,2\%). A reação prosseguiu com agitação em banho-maria a uma temperatura de $45{ }^{\circ} \mathrm{C}$ por 60 min (Figura 4a). Posteriormente, a mistura foi transferida para um funil de separação. Para facilitar o processo de decantação adicionou-se $5 \mathrm{~mL}$ de glicerina P.A ao funil de separação. A glicerina adicionada, juntamente com a glicerina produzida (fase mais densa, inferior), foi removida por decantação, sendo então isolado o biodiesel (fase menos densa, superior) (Figura 4b).

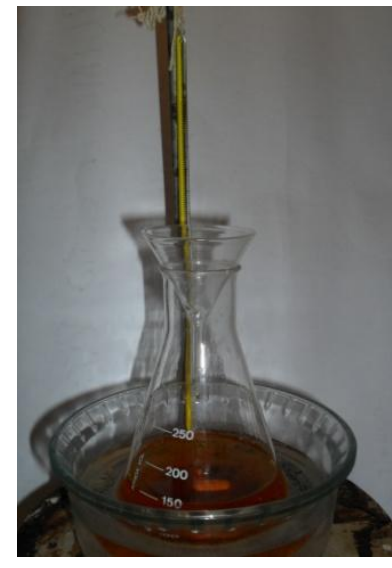

(a)

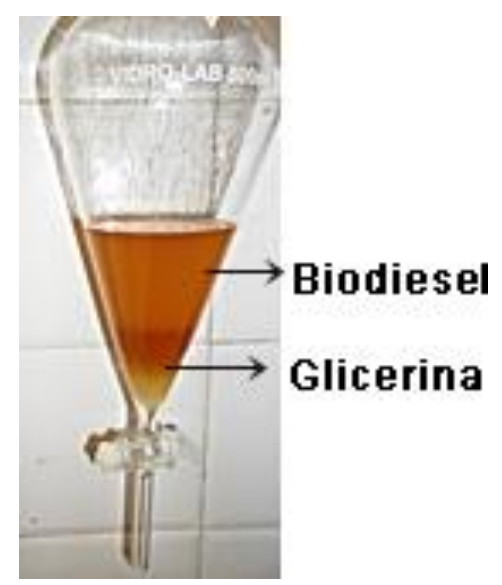

(b)

Figura 4. (a) Sistema de reação; e (b) Separação das fases do biodiesel e glicerina após transesterificação do óleo de fritura com o etanol. 


\section{Abordagem da atividade experimental}

Os alunos foram divididos em quatro grupos. O primeiro realizou a síntese de acordo com o que se propõe na literatura e considerando os itens (i) e (ii). O segundo procedeu da mesma maneira, mas, sem fazer uso do catalisador, $\mathrm{KOH}$. O terceiro realizou a reação sem agitação e o quarto, sem calor e sem agitação. Todos os grupos realizaram a atividade experimental simultaneamente. Após o término do experimento, foi iniciada uma discussão sobre o que cada grupo obteve e nesse momento relacionou-se os resultados obtidos com os conceitos químicos catalisador, energia de ativação, efeito da temperatura e agitação na velocidade de reação. Esses conceitos se inserem nos conteúdos de termoquímica e cinética que fazem parte do currículo do segundo ano do ensino médio. A elaboração das abordagens teóricas e da atividade experimental teve a duração de 02 meses. A intervenção didática foi vivenciada em cinco encontros de 03 horas, totalizando, 15 horas.

\section{Resultados e Discussão}

A figura 5 mostra os resultados do pré e pós-testes referentes às questões apresentadas na tabela 1 . Com relação à questão 1 , o pré-teste mostra que mais da metade dos alunos apresentou algum conhecimento sobre efeito estufa e seu benefício para o planeta, porém, o restante dos alunos julgou o feito estufa como sendo um fenômeno ruim, inclusive para a vida, "Ruim, porque aumenta a temperatura causando um desconforto, (A5)". O mesmo comportamento observou-se no que diz respeito à segunda questão. Um percentual pequeno de alunos, $6 \%$, respondeu satisfatoriamente: "O efeito estufa é quando os raios solares passam pela camada de $\mathrm{O}_{3}$, atinge a crosta terrestre e reflete para a atmosfera, mantendo assim a temperatura do nosso planeta", (A17).

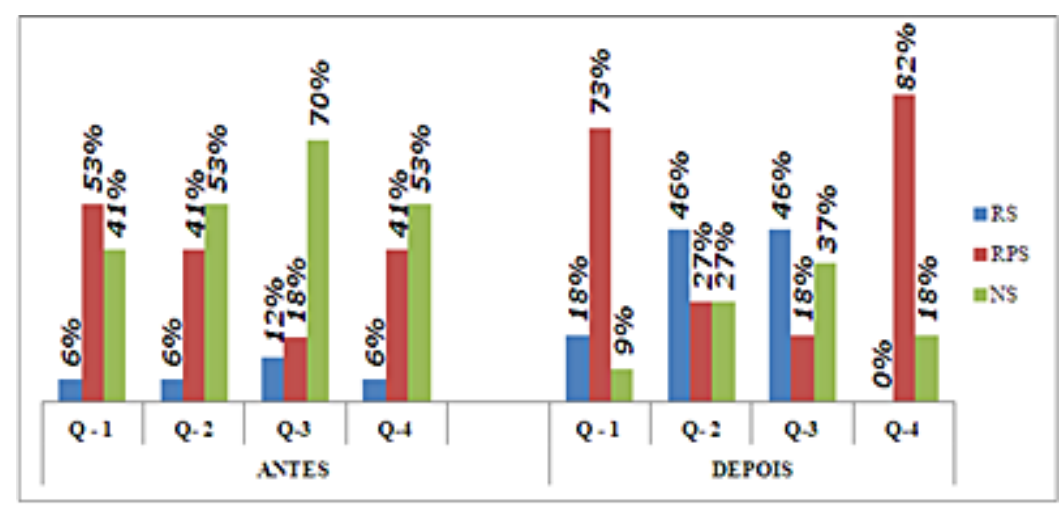

Figura 5. Resultados do pré e pós-teses referentes à tabela 1.

Os dados do pós-teste revelam uma evolução nas respostas dos alunos às questões propostas, evidenciando a importância que a intervenção didática proporcionou no entendimento dos alunos sobre efeito estufa, aquecimento global. Por exemplo, A5 comenta: "O efeito estufa é um efeito natural que a terra tem, esse efeito é bom, pois aquece a terra". No entanto, o 
resultado referente à questão 4 reflete uma incompreensão dos alunos, $18 \%$ de respostas não satisfatórias, sobre as alternativas para minimizar os problemas de aquecimento global.

$\mathrm{Na}$ terceira questão, antes da intervenção, a maioria dos alunos cita apena o gás $\mathrm{CO}_{2}$ como responsável pelo efeito estufa. No pós-teste quase metade dos alunos cita outros gases, " $\mathrm{CO}_{2} ; \mathrm{CFC} ; \mathrm{CO} ; \mathrm{SO}_{2}$ " como responsáveis pelo aumento no efeito estufa.

A figura 6 mostra os resultados do pré e pós-testes referentes às questões apresentadas na tabela 2. Na questão 1, 20\% os alunos responderam satisfatoriamente, sendo que após o pósteste esse percentual aumentou para $30 \%$. No entanto, boa parte dos alunos não consegue justificar o porquê de não existir água para consumo humano em abundância em nosso planeta. A escassez de água potável atinge dois bilhões de pessoas no mundo, sendo um bilhão em áreas urbanas. Caso a água doce continue a ser encarada como um bem infinito, o Programa das Nações Unidas para o Meio Ambiente (PNUMA) prevê que 2,7 bilhões de pessoas amargarão a sua falta até 2025 (Teixeira, 2007). A escassez é tratada como uma das consequências da contaminação de mananciais, da fragilidade do saneamento básico e dos usos e abusos da água potável e da intervenção humana (Watanabe \& Kawamura, 2005).

Na questão 2 do pós-teste, houve um aumento das respostas dos alunos em relação a se posicionarem no sentido de afirmar que há oxigênio dissolvido na água. No entanto, muitos deles mostraram dificuldades em discutir como isso ocorre. Nesses casos, os alunos conseguiram relacionar a respiração dos peixes ao oxigênio molecular dissolvido na água.

Pré-teste, A3: sim; pós-teste, A3: "Por conta dos animais aquáticos podemos identificar a presença de oxigênio. Na questão 3, no pré-teste, não houve respostas satisfatórias e um elevado percentual de respostas insatisfatórias, $80 \%$. No pós-teste, mais da metade dos alunos, 53\% afirmou que sim, mas não abordaram sobre o equilíbrio gasoso entre a atmosfera e a água nos rios. Na questão 4, mais da metade dos alunos que não respondeu o pré-teste, após a intervenção conseguiu dar respostas parcialmente satisfatórias, $60 \%$, e $6 \%$ satisfatória, por exemplo, A5, comenta: "O óleo de fritura polui as águas do mar e assim acabam o oxigênio dissolvido na água. Os animais aquáticos precisam de oxigênio".

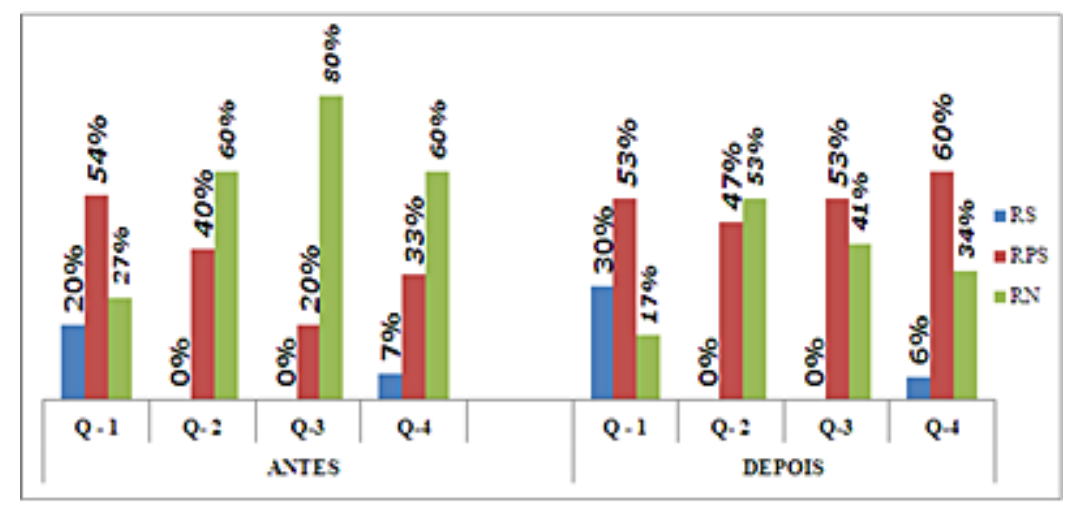

Figura 6. Resultados do pré e pós-teses referentes à tabela 2. 
A figura 7 mostra os resultados do pré e pós-testes referentes às questões apresentadas na tabela 3. Para as questões 1 , 2 e 3 propostas não houve respostas satisfatórias. É importante destacar que na questão 1 do pós-teste, mais de $90 \%$ dos alunos consegue responder sobre a diferença entre um óleo e uma gordura, porém todas as respostas são parcialmente satisfatórias: A2: "Por causa da estrutura das moléculas". Na questão 2, do pós-teste, $13 \%$ dos alunos consegue dar respostas satisfatórias com relação às alternativas para reciclagem do óleo de fritura: $A 3$, " sabão, cola de vidraceiro, biodiesel e ração".

$\mathrm{Na}$ questão 3, observa-se uma evolução significativa na quantidade de alunos que consegue responder de forma parcialmente satisfatória sobre a substituição do combustível oriundo do petróleo no motor ciclo diesel para o biodiesel. Na questão 4, mais de $87 \%$ dos alunos, no pós-teste consegue citar algumas matérias-primas para produção de biodiesel:

Pré-teste, A9: "Carvão"; pós-teste, A9; óleo vegetal e de fritura, mamona".

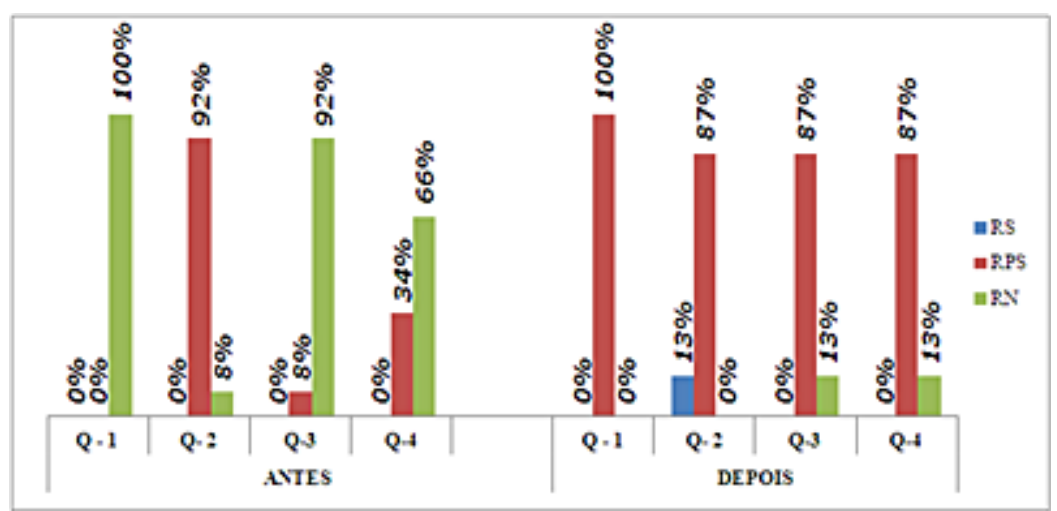

Figura 7. Resultados do pré e pós-teses referentes à tabela 3.

De uma forma geral, os resultados dos questionários mostraram que a vivência de uma abordagem CTS proporcionou uma evolução conceitual dos alunos em relação aos temas aquecimento global, efeito estufa, poluição da água, descarte incorreto do óleo de fritura.

\section{Atividade experimental}

A reação entre o álcool, em nosso caso o etanol, com o catalisador alcalino $\mathrm{KOH}$, permite a formação do etóxido de potássio, de acordo com a equação química 1 , descrita a seguir:

$$
\begin{array}{ll}
\mathrm{CH}_{3} \mathrm{CH}_{2} \mathrm{OH}+\mathrm{KOH} \rightleftharpoons \mathrm{CH}_{3} \mathrm{CH}_{2} \mathrm{O}^{-} \mathrm{K}^{+}+\mathrm{H}_{2} \mathrm{O} & \text { Equação } 1 \\
\text { É esse etóxido, } \mathrm{CH}_{3} \mathrm{CH}_{2} \mathrm{O}^{-} \mathrm{K}^{+} \text {, que, de fato, age como catalisador na reação de }
\end{array}
$$
transesterificação entre o óleo (triglicerídeo) e o etanol remanescente formando o biodiesel, como exposto na figura 1. É sabido que o biodiesel produzido com etanol apresenta menor rendimento e maior dificuldade de formação, especialmente quando comparado ao metanol, por esse favorecer a formação de sabão e maior miscibilidade que o biodiesel, o que dificulta sua separação da glicerina. Entretanto, ao se adicionar a glicerina pura após a reação, essa separação 
é possivel por permitir a desestabilização da emulsão formada por espécies tais como os sais dos ácidos graxos (sabões), mono e diglicerídeos e fosfolipídeos que agem como surfactantes (Cavalcante et al, 2010). Como o principal foco da síntese do biodiesel nas aulas apresentadas foi o de perceber a reação química, numa perspectiva contextualizada e para alunos do ensino médio, não nos detivemos na sua posterior purificação e caracterização, sendo então o experimento finalizado na separação das fases. É preciso deixar registrado que quando discutido, a seguir, o rendimento da reação, não estamos nos referindo à conversão completa do triglicerídeo em biodiesel, e sim ao volume da fase que contém o biodiesel, comparativo entre as quatro reações processadas em diferentes condições.

Como o segundo grupo procedeu com o experimento sem a adição do $\mathrm{KOH}$, e consequentemente sem a presença do catalisador etóxido de potássio, o mesmo não obteve êxito na produção do biodiesel, não percebendo então a formação das duas fases que caracteriza a formação do biodiesel e glicerina, ao término da atividade, comparado às demais reações processadas na presença do catalisador.

Foi discutido que para uma reação química ocorrer de forma mais rápida, a mistura reacional precisa ultrapassar uma barreira, denominada de energia de ativação $\left(E_{a}\right)$, ou seja, as espécies químicas ao coliderem necessitam de uma energia cinética suficiente para ultrapassar a barreira de ativação e formar o produto desejado. Nesse sentido o papel dos catalisadores é permitir criar produtos intermediários durante a reação a fim de diminuir essa barreira permitindo que a reação se processe de modo ainda mais rápido (Atkins, 2006) (figura 8).

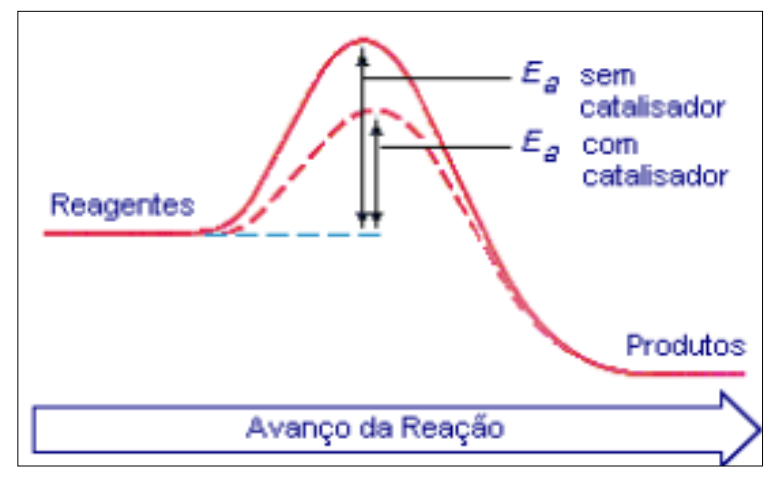

Figura 8. Reação química com e sem uso do catalisador.

O terceiro e quarto grupos procederam a reação sem agitação e sem agitação e aquecimento, respectivamente. Eles observaram que há formação do biodiesel, mas não obtiveram o rendimento esperado. A reação com agitação e aquecimento favorece um aumento nas colisões das espécies reagentes e consequentemente na sua velocidade, contribuindo para obtenção de um melhor rendimento. Por isso o primeiro grupo, que obteve o experimento na presença do catalisador, sob agitação e aquecimento, obteve melhor resultado (maior volume da fase superior contendo o biodiesel) frente aos demais grupos. 


\section{Considerações Finais}

De uma forma geral, os resultados dos questionários mostraram que a vivência de uma abordagem CTS proporcionou uma evolução conceitual dos alunos em relação aos temas aquecimento global, efeito estufa, poluição da água, descarte incorreto do óleo de fritura. Além disso, a intervenção vivenciada permitiu relacionar essas temáticas com os conteúdos escolares, como energia de ativação, reação de transesterificação, catalisador, velocidade de reação, princípio de Le Chatelier e estequiometria de reação. A doação pelos alunos do óleo de fritura os estimulou a não realizar um descarte inadequado desse óleo em suas residências. Além disso, eles constataram que o óleo de fritura pode ser utilizado para o desenvolvimento de atividades experimentais na escola, pois a partir do óleo que eles doaram e do tratamento químico realizado, obtiveram o biodiesel. A atividade experimental também permitiu correlacionar a temática biodiesel com os conceitos químicos aqui descritos. A intervenção didática vivenciada possibilitou uma interação mais próxima acerca de uma problemática que para muitos da escola EREM - Prof. Cândido Duarte era vista como uma realidade distante. Os alunos se sentiram bastante motivados, participaram de todas as atividades e utilizaram os conhecimentos adquiridos numa gincana que ocorreu em um momento posterior ao desenvolvimento desse projeto na escola. Umas das dificuldades que os estudos apontam na implementação de uma prática pedagógica pautada nas relações CTS em sala de aula está na pouca disponibilidade de material didático adequado que suporte as discussões de temas específicos em sala de aula. Nesse sentido, esse estudo pode contribuir, pois a intervenção didática constituída pelas abordagens teóricas e atividade experimental está disponível podendo ser utilizada por outros professores que queiram desenvolver um trabalho similar. $O$ trabalho realizado teve reconhecimento na mídia local, sendo a coordenadora do LOB, Professora Claudia C. C. Bejan, convidada pela Secretaria do Estado de Pernambuco para estender o estudo realizado na EREM Professor Cândido Duarte a outras escolas integrais de Pernambuco. 


\section{Referências}

ACEVEDO ROMERO, P.; ACEVEDO DIAZ, J. A. Proyectos y materiales curriculares para la educacion CTS: enfoques, estructuras, contenidos y ejemplos. Bordón, Madri, v. 54, n.1, p. 5-18, 2002. Disponível em: http://www.campus-oei.org/salactsi/acevedo9.htm. Acessada em 15 de abril de 2012.

ALMEIDA, M. A. V; AMARAL, E. M. R.; BARBOSA, L. F.; MELO, S. H. D. Ampliando a formação no contexto escolar: a implantação de uma escola de formação docente e discente em Pernambuco. In: Colóquio Internacional Educação \& Contemporaneidade, 4. CD-ROM, 22 a 24 de setembro de 2010, Campus UFS, São Cristovão/SE. Disponível em:

http://www.educonufs.com.br/ivcoloquio/cdcoloquio/eixo_02/E2-116a.pdf. Acessada em 19 de janeiro de 2011.

ATKINS, P.; JONES, L. Princípios de química: questionando a vida moderna e o meio ambiente. 3 ed. Porto Alegre: Bookman, 2006.

BEJAN, C. C. C.; SILVA, A. M. Proposta de produção de biodiesel em Pernambuco a partir de óleo de fritura. Anais da Academia Pernambucana de Ciência Agronômica, Recife, v. 7, p. 272-285, 2010.

CASTRO, H. F. Processos Industriais II. Faculdade de Engenharia Química de Lorena. Apostila 5, p.7, 2001.

CAVALCANTE, K. S. B.; PENHA, M. N. C.; MENDONÇA, K. K. M.; LOUZEIRO, H. C.; VASCONCELOS, A. C. S.; MACIEL, A. P.; SOUZA, A. G.; SILVA, F. C. Optimization of transesterification of castor oil with ethanol using a central composite rotatable design (CCRD). Fuel, v. 89, p. 1172-1176, 2010.

CHARPE, T. W.; RATHOD, V. K. Biodiesel production using waste frying oil. Waste Management, v. 31, n.1, p. 85-90, 2011.

CORTEZ, H. Aquecimento global e água. Série consciência e meio ambiente, 2004, 94p.

COSTA NETO. P. R.; ROSSI, L. F. S.; ZAGONEL G. F.; RAMOS L. P. Produção de biocombustível alternativo ao óleo diesel através da transesterificação de óleo de soja usado em frituras. Química Nova, v. 23, n.4, p. 531-537, 2000.

ESTEVES, F.A. Fundamentos de limnologia. 2ª ed. Rio de janeiro: Interciência, 1998.

FIORUCCI, A. R.; EDEMAR, B. F. A importância do oxigênio dissolvido em ecossistemas aquáticos. Química Nova na Escola, v. 22, n.2, p. 10 -16, 2005.

FIRME, R. do N.; AMARAL, E. M. R. do. Analisando a implementação de uma abordagem CTS na sala de aula de química. Ciência \& Educação, v. 17, n. 2, p. 383-399, 2011.

R. B. E. C. T., vol 6, núm. 2, mai-ago.2013 ISSN - 1982-873X 
Geris, R.; SANTOS N. A. C.; AMARAL, B. A.; MAIA, I. S.; CASTRO, V. D.; CARVAlhO, J. R. M. Biodiesel de soja - reação de transesterificação para aulas práticas de química orgânica. Química Nova, v. 30, n. 5, p. 1369-1373, 2007.

GODOY, S.G. M.; JOÃO, B. P. O Protocolo de Kyoto e os países em desenvolvimento. Pesquisa \& Debate, v. 18, n. 2, p. 329-353, 2007.

KOVALSKI, M. L.; ANA, T. O. Concepções sobre aquecimento global por professores do ensino fundamental. Fórum ambiental da alta paulista, v.3, p.14, 2007.

LAM, M. K.; LEE, K. T.; MOHAMED, A. R. Homogeneous, heterogeneous and enzymatic catalysis for transesterification of high free fatty acid oil (waste cooking oil) to biodiesel: A review. Biotechnology Advances, v. 28, p.500-518, 2010.

LÜDKE, M.; ANDRÉ, M.E.D.A. Pesquisa em educação: abordagens qualitativas. São Paulo: EPU, 1986.

MARCONDES, M. E. R.; CARMO, M. P. do; SUART, R. C.; SILVA, E. L. da; SOUZA, F. L. SANTOS JR, J. B.; AKAHOSHI, L. H. Materiais instrucionais numa perspectiva CTSA: uma análise de unidades didáticas produzidas por professores de química em formação continuada. Investigações em Ensino de Ciências, v. 14, n.2, p. 281-298, 2009.

OLIVEIRA, M. M. Como fazer: projetos, relatórios, monografias, dissertações e teses. Recife: Edições Bagaço, 2003.

OLTRA, C.; PRIOLO, V. Un análisis exploratorio de la percepción pública de los biocombustibles. An exploratory analysis of public perceptions of biofuel. Revista CTS, n. 20, v.7. 2012. http://revistacts.net/files/Volumen\%207\%20-\%20N\%C3\%BAmero\%2020/Oltra_EDITADO.pdf . Acessado em 27 de julho de 2012.

RABELO, R. A.; FERREIRA O. M. Coleta seletiva de óleo de fritura para aproveitamento industrial. Disponível em: http://pt.scribd.com/doc/55543801/COLETA-SELETIVA-DE-OLEO-RESIDUAL-DEFRITURA-PARA-AP. Acessado em 10 de fevereiro de 2009.

SANTOS, A. P. B.; PINTO, A. C. Biodiesel: Uma Alternativa de Combustível Limpo. Química Nova na Escola, v. 31, n.1, p. 58-62, 2009.

SANTOS, W. L. P. dos; GALIAZZI, M. do C.; PINHEIRO JUNIOR, E. M.; SOUZA, M. L. de; PORTUGAL, S. O enfoque CTS e a Educação Ambiental: Possibilidades de "ambientalização" da sala de aula de Ciências. In: SANTOS, W. L. P. dos; MALDANER, O. A. (Orgs). Ensino de Química em Foco. ljuí: Ed. Unijuí, 2011, p. 368.

SILVA, C. N.; ANDERSON, C. L.; ROCHEL, M. L.; ZENILDA L. C.; ANA, L.Q. Ensinando a Química do Efeito Estufa no Ensino Médio. Química Nova na Escola, v. 31, n.4, p. 268- 274, 2009. 
THAIYASUIT, P.; PIANTHONG, K.; WORAPUN, I. Acid Esterification-Alkaline Transesterification Process for Methyl Ester Production from Crude Rubber Seed Oil. Journal of Oil Science, v. 61, p. 81-88, 2012.

TOLENTINO, M.; ROCHA-FILHO, R. C. A química no efeito estufa. Química Nova na Escola, v. 8, n.2, p 10-14, 1998.

TEIXEIRA, A.C. Educação ambiental: caminho para a sustentabilidade. Revista brasileira de educação ambiental / Rede Brasileira de Educação Ambiental, n.2, p. 23-31, 2007.

WATANABE, G.; KAWAMURA, M.R.D. Em busca de espaços curriculares para a questão da água. In: Nardi, R. (Ed.). V Encontro Nacional de Pesquisa em Ensino de Ciências, Bauru. 2005.

Leandro de Araújo Azevedo é licenciando em Química - Departamento de Química - Universidade Federal Rural de Pernambuco. E-mail: leandroazevedo21@yahoo.com.br.

Claudia Cristina Cardoso Bejan é Bacharel em Química - UFPE, Mestre e Doutora em Química UFPE, é docente do Departamento de Química - Universidade Federal Rural de Pernambuco UFRPE. E-mail: claudiacardoso75@gmail.com.

Angela Fernandes Campos é Química Industrial e Mestre em Química pela UFPB, Doutora em Química pela UFPE, é docente do Departamento de Química- Universidade Federal Rural de Pernambuco e membro permanente do Programa de Pós-graduação em Ensino de Ciências Nível Mestrado. E-mail: afernandescampos@gmail.com.

Maria Angela Vasconcelos de Almeida é Química Industrial e Mestre em Química - UFPE, Doutora em Educação - UFPE, é docente do Departamento de Química- Universidade Federal Rural de Pernambuco. E-mail: angela.vasc@uol.com.br 